\title{
Cidade viva e sonora da terra de Guairacá: experimentações sonoras acerca da história de Curitiba com crianças na Bienal de Arte
}

\author{
Live and sound city of the land of Guairacá: sound experimentation \\ on the history of Curitiba with children at the Art Biennial
}

\section{Ciudad viva y sonora en la tierra de Guairacá: experimentos sonoros sobre la historia de Curitiba con niños en la Bienal de Arte}

João Paulo de Souza da Silva'

https://orcid.org/0000-0002-7557-5226

Daniele Martinez de Oliveira Coelho²

https://orcid.org/0000-000 I-6447-2I 52

\begin{abstract}
Resumo: Neste texto, relatamos a experiência com a proposta artística "Cidade viva e sonora da terra de Guairacá", realizada com estudantes do $5^{\circ}$ ano de uma escola municipal e apresentada na IV Bienal de Arte/Educação da Secretaria Municipal da Educação de Curitiba no segundo semestre de 2019. O objetivo principal da proposta foi articular a temática estabelecida pela Bienal - "Arte e Vida: fronteiras em aberto" - com os conteúdos ministrados em outros componentes curriculares, como história e geografia. Imaginamos a possibilidade de a partir da realidade vivida pelos estudantes atuar poeticamente através de fronteiras não apenas geográficas (cidade de Curitiba), mas temporais (século XIX), com a criação e captação de paisagens sonoras produzidas pelos alunos, utilizando diferentes materiais sonoros, posteriormente editados, cujo resultado se caracteriza como uma composição de música contemporânea, apoiando-se especialmente em Schafer (199| e 200I), Zagonel (1999 e 2007), Torres e Kozel (2019).
\end{abstract}

Palavras-chave: Relato de experiência. IV Bienal de Arte/Educação de Curitiba. Paisagem sonora.

Abstract: In this text, we report the experience with the artistic proposal "Living and sounding city of the land of Guairacá", carried out with 5th grade students from a municipal school and presented at the IV Art/Education Biennial of the Municipal Department of Education of Curitiba in the second half of 2019. The main objective of the proposal was to articulate the theme established by the Biennial - "Art and Life: open borders" - with the content taught in other curriculum components, such as history and geography. We imagined the possibility of starting from the reality lived by the students to poetically act across borders not only geographic (city of

\footnotetext{
I Doutor em Educação pelo PPGE/UFPR. Professor da Secretaria Municipal de Educação de Curitiba/PR. E-mail: jpaulodesouza@hotmail.com

2 Mestranda em Educação pelo PPGE/UFPR. Especialista em Metodologia do Ensino de Artes pela UNINTER. Professora das Secretarias Municipais de Educação de Curitiba/PR e de Colombo/PR. E-mail: dani.martinezcoelho@gmail.com
} 
Curitiba), but temporal (19th century), with the creation and capture of soundscapes produced by the students, using different sound materials, later edited, whose result is characterized as a contemporary music composition, relying especially on Schafer (I99I and 200I), Zagonel (I999 and 2007), Torres and Kozel (2019).

Keywords: Experience report. IV Biennial of Art / Education of Curitiba. Sound landscape.

Resumen: En este texto, relatamos la experiencia con la propuesta artística "Ciudad viva y sonora de la tierra de Guairacá", realizada con alumnos de $5^{\circ}$ grado de una escuela municipal y presentada en la IV Bienal de Arte $/$ Educacion de la Educación Municipal de Curitiba en el segundo semestre de 2019. El objetivo principal de la propuesta fue articular la temática establecida por la Bienal - "Arte y Vida: fronteras abiertas" - con los contenidos impartidos en otros componentes curriculares, como historia y geografía. Imaginamos la posibilidad de actuar poéticamente desde la realidad vivida por los estudiantes a través de fronteras no solo geográficas (ciudad de Curitiba), sino temporales (siglo XIX), con la creación y captura de paisajes sonoros producidos por los estudiantes, utilizando diferentes materiales sonoros, posteriormente editados, cuyo resultado se caracteriza por ser una composición de música contemporánea, apoyándose especialmente en Schafer (I991 y 200I), Zagonel (1999 y 2007), Torres y Kozel (2019).

Palabras-clave: Informe de experiencia. IV Bienal de Arte / Educación de Curitiba. Paisaje sonoro.

\section{Introdução}

Na experiência em análise, partimos das expectativas e ideias de uma turma de estudantes do $5^{\circ}$ ano do Ensino Fundamental da rede pública municipal de Curitiba, buscando a interdisciplinaridade entre os conteúdos ministrados em outros componentes curriculares, especialmente história e geografia, articulados ao tema “Arte e Vida: Fronteiras em Aberto” da IV Bienal de Arte/Educação da cidade de Curitiba do ano de 2019.

Nossa participação foi na modalidade de "Exploração e produção sonora" com a proposta artística intitulada "Cidade viva e sonora da terra de Guairacá3”", por meio da mostra desenvolvida pela Secretaria Municipal da Educação em conjunto com a Bienal Internacional de Curitiba que, de forma inédita, integrou a primeira etapa do referido evento no Centro Cultural do Portão (Museu Metropolitano de Arte de Curitiba - MuMA)4, apenas com trabalhos desenvolvidos por estudantes da Educação Infantil e Ensino Fundamental de diferentes faixas etárias com o apoio de seus professores e em diferentes linguagens e propostas dialogando com o tema.

Imaginamos com isso a possibilidade de, a partir da realidade vivida pelos estudantes, atuar poeticamente através de fronteiras não apenas geográficas, mas também temporais, com a criação e captação de paisagens sonoras produzidas por eles, posteriormente editadas, cujo resultado se caracteriza como composição de música contemporânea.

\footnotetext{
${ }^{3}$ Escolhemos "terra de Guairacá" fazendo alusão ao Hino de Curitiba (com letra de Ciro Silva e música de Bento Mossurunga - 1967). Guairacá é o nome do grande chefe indígena das 12 tribos guaranis (Cacique Guairacá).

${ }^{4}$ Endereço: Av. República Argentina, 3.430 - Portão, Curitiba/PR. Contato: (4I) 3229-4482. Mais informações: portaocultural@fcc.curitiba.pr.gov.br Horário de funcionamento: das IOh às I9h (de terça a domingo).
} 


\section{Revisão de Literatura}

De acordo com a Base Nacional Comum Curricular (BNCC), promulgada em 2017, o componente curricular (ou disciplina) Arte deve contemplar as quatro linguagens artísticas: música, dança, teatro e artes visuais. Sendo que elas:

[...] articulam saberes referentes a produtos e fenômenos artísticos e envolvem as práticas de criar, ler, produzir, construir, exteriorizar e refletir sobre formas artísticas. A sensibilidade, a intuição, o pensamento, as emoções e as subjetividades se manifestam como formas de expressão no processo de aprendizagem em Arte. (BRASIL, 2017, p. 193).

Podemos dizer que as artes integradas são uma "novidade" da BNCC. De modo geral, o que se pretende é que em suas práticas os estudantes desenvolvam relações entre as diferentes linguagens, incorporando, por exemplo, numa mesma atividade elementos das artes visuais, da música, do teatro e da dança de maneira conjunta. Há também a previsão de que os trabalhos em Arte se articulem com os usos das tecnologias da comunicação e informação (TIC's). Outra possibilidade com a abordagem é relacionar as várias linguagens artísticas, buscando desenvolver diálogos com outros campos do conhecimento - ciências, educação física, história, geografia etc. -, possibilitando uma ampliação do processo de aprendizagem.

Assim, o trabalho na abordagem das artes integradas propõe diferentes possibilidades de aproximações:

a) Multidisciplinar: mais de uma disciplina, mas não há relação de uma com a outra e nem resultado integrado;

b) Pluridisciplinar: há cooperação entre as disciplinas, porém sem coordenação. Existe troca entre elas, mas não organizada, normalmente pelo estudo do mesmo objeto em várias disciplinas ao mesmo tempo;

c) Interdisciplinar: quando temos um intercâmbio e interação coordenados dos conhecimentos, integração dos resultados obtidos, permanecendo as metodologias e especificidades de cada disciplina;

d) Transdisciplinar: há tamanha interação e integração global dos vários saberes, que não é mais possível separar as disciplinas.

Temos desse modo por meio da proposta apresentada na BNCC uma perspectiva de trabalho que integra as diferentes disciplinas, sendo que para isso é essencial que os professores compreendam que, ao se pretender desenvolver trabalhos interdisciplinares para sala de aula, dialogam diferentes saberes, logo buscamos evitar que algumas áreas no trabalho possuam prevalência sobre as demais. Sem que se tome todas as disciplinas como iguais em importância é impossível pensar numa abordagem 
interdisciplinar do trabalho educativo. Esse também foi o entendimento adotado pela curadoria da Bienal:

Assim, quando o professor estiver abordando determinado conteúdo de Artes Visuais, [...], deve pensar na possibilidade de integrar uma outra linguagem artística. Supondo-se que no $5^{\circ}$ ano seja desenvolvido um trabalho a partir da linguagem/técnica de uma instalação (suporte comumente relacionado à Arte Contemporânea), é possível combinar dispositivos sensoriais (objetos sonoros) que remetam a vários sentidos desta instalação, e dentro do mesmo contexto abordar conteúdos específicos de Artes Visuais e/ou também de Música (CURITIBA, 202I, p. 18).

Nessa perspectiva de trabalho com Arte na escola, a Bienal de Arte/Educação da Secretaria Municipal da Educação (SME) de Curitiba historicamente teve início na década de 1990, por meio de mostras de trabalhos artísticos, realizados pelos estudantes, demonstrando as mudanças que foram ocorrendo no ensino de Arte durante esse período. Com o objetivo de integrar as mostras das diferentes linguagens artísticas em um único evento, em 2005 "criou-se a I Jornada Municipal de Artes, composta pela Mostra de Artes Visuais e de Teatro, denominada enCena" (CURITIBA, 2020, p. 22).

Em 2008, os Centros Municipais de Educação Infantil (CMEls) integraram a Jornada Municipal de Artes, que antes contava apenas com o Ensino Fundamental (unidades escolares). Assim, em 2009 "aconteceu a primeira edição do Seminário de Arte. No ano de 20II, as equipes de Arte da Secretaria Municipal de Educação (SME) promoveram reflexões internas acerca das novas tendências para mostras de Arte" (Ibid.).

A I Bienal de Arte/Educação da RME surgiu a partir dessa nova perspectiva de ter um "novo perfil para as mostras dos trabalhos desenvolvidos na área de Arte" (Ibid.). Em 20II, a Bienal foi "divulgada durante o III Seminário de Arte [...], que passou a ocorrer num intervalo de dois anos" (Ibid.). Com isso, em 2012 "ocorreu a Mostra da I Bienal de Arte/Educação, "palco" para os profissionais da educação, estudantes e crianças compartilharem suas práticas em Arte” (Ibid.). A temática escolhida foi "Olhos e Olhares: Espelho da Cidade" e ocupou "diferentes espaços da cidade, dividida em três linguagens: Artes Visuais, Música e Teatro" (lbid.).

A II Bienal (20|3-20|4) teve como temática "Vozes e Silêncio". Essa edição "incluiu a Mostra Educultura, que tinha por intuito dar visibilidade aos resultados desse projeto, assim como socializar a produção artística realizada pelos profissionais participantes" (Ibid.).

Em 2015-2016, tivemos a edição da III Bienal com a temática "Lugares Transitórios”, que "permeou a formação continuada do presente ano" (lbid.).

Em 2018, "integrou-se à comissão da Bienal de Arte/Educação a Gerência de Educação e Cultura, setor responsável pela captação e difusão cultural para os profissionais da educação" 
(CURITIBA, 2020, p. 22). Com isso, a IV Bienal de Arte/Educação da SME de Curitiba, durante o seminário preparatório nesse ano, discutiu a temática "Arte e Vida":

[...] em sete mesas-redondas com profissionais de artes, professores e artistas das diferentes linguagens e os profissionais da educação atuantes na Educação Infantil, no componente curricular Arte, Práticas Artísticas e Projetos de Música no Ensino Fundamental. A IV Bienal de Arte/Educação da SME buscou estabelecer um diálogo entre as produções artísticas realizadas pelas unidades educacionais com a Arte Contemporânea, com vistas à ampliação do olhar estético para os processos educativos e criativos. Nesse sentido, a IV Bienal propôs a temática "Arte e Vida: Fronteiras em Aberto", como desafio a ser representado, desvelado, codificado pelas múltiplas linguagens da arte. A temática "Arte e Vida" dialogou com a temática "Fronteiras em Aberto" proposta pela Bienal Internacional de Curitiba e, de forma inédita, integrou a primeira etapa da referida bienal. (CURITIBA, 2020, p. 23).

Conforme afirma Zagonel (1999, p. I): "Nessas novas propostas sempre está expressa a necessidade de maior abertura quanto à maneira de ensinar e aos conteúdos a tratar, junto com a exploração do som e a invenção". Portanto, "partindo da experimentação da criança, pretende-se despertá-la e sensibilizá-la para a música” (Ibid.). A autora ainda enfatiza, ao falar da música contemporânea, que "[...] se a criança sabe fazer, seguramente saberá ouvir melhor. Sem dúvida o "fazer musical" é um meio imprescindível para o desenvolvimento de certas competências necessárias à formação do aluno" (Ibid., p. 3). Com isso, ela destaca o papel fundamental da música contemporânea na educação musical,

[...] pois ela permite que se trabalhe com todo o mundo sonoro descoberto pela criança quando ela era ainda pequena. Para Agosti-Gherban e Rapp-Hess, a arte sonora contemporânea é a música das crianças, pois é uma expressão atual e, consequentemente, da sua época. A criança já possui, por sua natureza, curiosidade em relação ao som; ela faz pesquisas sozinha e quer descobrir. A intervenção pedagógica a auxilia a transformar esta atitude em ação consciente, para em seguida elaborar seus próprios processos. (ZAGONEL, 1999, p. 2).

A Arte Contemporânea, segundo a curadora da IV Bienal de Arte/Educação da Secretaria Municipal de Curitiba, Prof. ${ }^{a}$ Dr. ${ }^{a}$ Deborah Bruel ${ }^{5}$,

[...] é marcada pela mescla entre as linguagens artísticas, pela indistinção das fronteiras entre as disciplinas e por um hibridismo técnico. Em cada momento histórico, a arte relacionou-se de diferentes maneiras com a vida cotidiana, servindo de ponto de partida para refletirmos sobre os porquês e as urgências da arte, que ora nos afeta e dá vida, ora a vivemos. (BRUEL, 2018 apud CURITIBA, 2020, p. 24).

Enquanto arte experimental, a música contemporânea é capaz de propor exercícios a nossa

5 Deborah Alice Bruel Gemim: Artista visual, doutora em Artes Visuais ECA/USP, professora na EMBAP/UNESPAR. Últimos trabalhos: exposição Estratégias do Feminino, Farol Santander Porto Alegre, 2019; exposição HACIA EAC Montevidéu, 2019; Publicou com Juliana Gisi a tradução Michael Fried [...] ARS São Paulo n. 28, 2016. (CURITIBA, 2020, p. 25). 
mente divergentes dos habituais, uma vez que sua estrutura é diferente daquela conhecida por nós. De acordo com Oliveira (2010, p. 214) “[...] aventurar-se no ambiente desafiador da música contemporânea exige esforço, quebra de hábitos de escuta e a formação de novas crenças estéticas; é preciso disposição para se libertar da direcionalidade indutiva-dedutiva da escuta tonal". Lembramos que foi ao longo do século $X X$ que ocorreu

[...] a valorização do timbre e a inclusão do ruído como elemento passível de ser transformado em música, uma nova visão do silêncio e do espaço, as diferentes abordagens de ritmo e métrica, novos usos do gesto, a criação de diferentes grafias e a influência da tecnologia na estética musical. (ZAGONEL, 2007, p. 2).

Compreendendo a arte como reflexo da vida, manifestando a irracionalidade do espaço vivido com suas múltiplas expressões sensoriais (visual, sonora, tátil, olfativa etc.), num diálogo com o cotidiano vivido pelos estudantes, os docentes lhes propuseram a elaboração de pesquisa acerca do processo de urbanização/industrialização da cidade de Curitiba ao longo do século $X X$, pretendendo desenvolver as diferentes paisagens sonoras da cidade durante esse período.

Dessa forma, a proposta procurou possibilitar aos estudantes e ao público o desenvolvimento de uma escuta mais ativa e reflexiva sobre os ambientes sonoros que os cercam. Assim, o trabalho pretendeu não apenas a ideia de uma escuta ativa e consciente dos sons do ambiente, um "ouvido pensante" (SCHAFER, 199I), aquilo que tem sido chamado de soundscape composition ${ }^{6}$ (traduzido como composição de paisagem sonora), mas também imaginar a paisagem sonora da Curitiba do passado como uma tarefa interessante para se refletir sobre a atual.

Assim, procuramos perceber os sons do nosso cotidiano, os da natureza: pássaros, chuva, galhos balançando, trovões etc.; e os da cidade: veículos, máquinas, pessoas, carros de comércio, como carro do ovo, sonhos, pamonhas, verduras e semelhantes. Esses sons compõem a nossa paisagem sonora, que nos traz vínculo afetivo a partir da percepção dos sons que nos remetem a espaços onde vivemos.

\footnotetext{
${ }^{6}$ A palavra soundscape foi um neologismo introduzido por Schafer, que pretendia criar uma analogia com a palavra Landscape (paisagem). A paisagem sonora, segundo o autor, seria então: "o ambiente sonoro. Tecnicamente, qualquer porção do ambiente sonoro vista como um campo de estudos." (Schafer, 1997, p. 366). Inicialmente, o Word Soundscape Project (WSP) tinha como preocupação analisar o ambiente acústico a sua volta e realizar um mapa sonoro das regiões estudadas (geralmente o próprio Canadá) criando um catálogo dos sons característicos de cada região. Decorrência direta desse estudo foi a preocupação com as mudanças que estavam acontecendo nos ambientes acústicos gerados pela industrialização das sociedades, e a correspondente inserção do som contínuo ou repetitivo (sons com características tipo-morfológicas estáveis) na paisagem sonora desses ambientes, sons produzidos pelos maquinários da era industrial, e que não são encontrados na natureza. (TOFFOLO; OLIVEIRA; ZAMPRONHA, 2003, p. 3).
} 
A paisagem sonora é nosso ambiente sonoro, o sempre presente conjunto de sons, agradáveis e desagradáveis, fortes e fracos, ouvidos ou ignorados, com os quais vivemos. Do zumbido das abelhas ao ruído da explosão, esse vasto compêndio em constante mudança, de cantos de pássaros, britadeiras, música de câmara ${ }^{7}$, gritos, apitos de trem e barulho da chuva têm feito parte da existência humana. A afinação do mundo (SCHAFER, 200I) é uma exploração pioneira da paisagem sonora. Uma tentativa de descobrir como era no passado, analisar e criticar o modo como é hoje e imaginar como será no futuro.

O grupo de estudantes pôde imaginar como era ouvir o trem na estação ferroviária, o badalar dos sinos da Catedral, a passagem do bonde, das carroças. Procuramos pensar marcos sonoros, que fazem parte da história da cidade, ainda que tenham sofrido alterações no espaço e no tempo e na percepção das pessoas acerca deles. O som produzido em uma paisagem em determinados espaços/tempos concede ao lugar uma identidade sonora única. Assim, essa paisagem sonora foi buscada, captada, reelaborada e redimensionada em cada período histórico pelo viés do que é fundamental para a época.

Pudemos também discutir o aumento do número de sons/ruídos no espaço curitibano, relacionado ao processo de urbanização/industrialização da cidade em Curitiba. Como na maioria das grandes cidades brasileiras, os automóveis são as maiores fontes sonoras. Porém, muitos dos sons não são fruto apenas de seus motores, mas também das chamadas para o comércio de hortifrutigranjeiros, produtos de limpeza, sonhos, churros etc. Tal proposta vai ao encontro das experimentações desenvolvidas pelo italiano Luigi Russolo, que em 1913 realizou estudo dos ruídos existentes e construiu instrumentos capazes de reproduzir esses sons. Em seu manifesto, escreveu que se o mundo moderno ganhou nova sonoridade, com suas máquinas e motores, assim também deve acontecer com a música (ZAGONEL, 2007).

Schafer (200I) forjou a noção de soundscape como o meio ambiente sonoro do homem. $\mathrm{Na}$ verdade, trata-se da contraparte acústica da paisagem que circunda os seres humanos. Deve-se distinguir entre os tipos de paisagens sonoras: a natural e outra cultural. $O$ soundscape natural envolve sonoridades que provêm de atividades ou ações físicas de fenômenos naturais. Já soundscapes culturais resultam de todo tipo de atividade humana. Marcam em especial o potencial comunicativo, emocional e expressivo do som. Chegar à música através do soundscape é um trajeto complexo. Seria demasiado simplista assumir que a música fosse apenas "destilada" do soundscape, justamente por também ocorrer o processo inverso, ou seja, a música tem a propriedade de influenciar e mesmo de caracterizar

\footnotetext{
${ }^{7}$ A música de câmara para uma definição rápida e contemporânea é uma reunião instrumental para um pequeno agrupamento, que realiza música escrita e que possui diversas possibilidades de formação, desde que limitada a no máximo dez instrumentistas (Souza Lima Blog. Acesso em: 12 fev. 202I).
} 
paisagens sonoras.

Uma paisagem sonora é tão diversificada quanto são diversos os ambientes que a produzem. Ela estará sempre impregnando a primeira impressão que se tem em campo e que se manifesta, infalivelmente, independente se há ou não discernimento prévio daquilo que o acontecimento sonoro significa. $O$ primeiro impacto sonoro é marcante e tão dilatador quanto à luz peculiar de uma região nova, as suas cores ou os odores que a compõem (TORRES; KOZEL, 20I0).

Diante do exposto, pensamos que a soundscape composition, ao colocar o ouvinte-compositor numa relação íntima com o ambiente sonoro, sugere uma atitude composicional que opera basicamente por meio da escuta, respeitando a dinâmica sonora do material. Assim, levando em consideração a possibilidade de o exercício da escuta e da composição de paisagem sonora ser uma proposta adequada a um fazer musical criativo, através de uma escuta que compõe, uma "escuta nômade"8, propomos nesse trabalho o exercício de uma escuta que inventa e atualiza ideias de música, a partir da escuta e gravação da "música dos sons da rua", e questionamos em que medida tal proposta possibilita a ampliação da própria ideia de música.

\section{Descrição da Experiência}

Compreendendo a arte como reflexo da vida com fronteiras em aberto, os estudantes do $5^{\circ}$ ano E, da Escola Municipal Araucária da SME de Curitiba, atuaram na construção de uma paisagem sonora para representar a Curitiba do século $X X$, refletindo sobre 0 processo de urbanização/industrialização. Cada momento sonoro está ligado a composições musicais que também são representativas de cada contexto histórico. Assim, a produção dos alunos convida a viver uma experiência que busca contar (e/ou imaginar) um pouco da história dessa cidade.

Do seu coração, na praça Tiradentes, onde em 1893 a hoje Catedral Basílica Menor substitui a antiga Igreja Matriz de Nossa Senhora da Luz dos Pinhais, passando pela "Rua das Flores", oficialmente $X V$ de Novembro outrora mata densa, onde se ouvia o som dos pássaros, os muitos pinheiros e o ir e vir das carroças. A via férrea que ligou Curitiba a Rio de Janeiro e São Paulo, no ano de 1909, tirando a terra dos pinhais de seu isolamento. $O$ bairro industrial de Rebouças, onde se estabeleceram diversas

\footnotetext{
${ }^{8} \mathrm{~A}$ ideia de escuta nômade [...] refere-se a uma escuta que cria um jogo que não se restringe a um ou outro modo de escuta, mas que simplesmente flui, passando de um modo a outro, sem restrições hierárquicas, semelhante à "invenção de escuta" imaginada por John Cage, na qual não há primazia da forma ou da expressão, por isso estaria aberta a operar de modo fluido e livre, nunca sendo retida pela espessura do material ou pelos limites do suporte. É uma escuta que se deixa arrastar pela "imaterialidade flexível do som", tal qual fala Mireille Buydens ao definir o que seria uma "música flutuante" em seu livro Sahara: l'esthétique de Gilles Deleuze (1990). (SANTOS, 2006, p. 4).
} 
fábricas: a de Mate por muito tempo sinônimo de Curitiba, cervejarias, moinhos de trigo, fábrica de fósforos, as muitas chaminés que soltavam sua fumaça no céu da cidade, tornando-a mais rica e a fazendo crescer. O Mercado Municipal, com sua atual sede de 1958, onde as pessoas negociavam os preços, ouvia-se a conversa alta de seus frequentadores em busca de frutas, legumes e grãos que não eram encontrados em outros lugares da cidade. Os carros de Curitiba, cidade impermeável, onde se chove sempre e o Sol nem sempre costuma aparecer, e claro as brincadeiras de roda, das ruas, que povoaram e enriqueceram a infância de Curitiba.

Com isso, conversamos com os alunos e iniciamos a proposta com estudo e pesquisa, que os levou a investigar com suas famílias, parentes e vizinhos (pessoas da terceira idade, como os avós, por exemplo), como era a cidade de Curitiba no século $X X$, refletindo sobre as seguintes questões: Como era viver nessa cidade? Quais eram seus trabalhos, sua rotina, as casas, as ruas? O que mais mudou de lá para cá? Como era a paisagem sonora?

Alguns alunos tiveram dificuldade para obter essas informações, pois suas famílias vieram de outras cidades (principalmente do interior do estado) e/ou não têm contato com pessoas que viveram nessa época. Contudo, aqueles que conseguiram tais informações, por meio dessa pesquisa direta com seus familiares, puderam compartilhar com a turma, e a busca continuou em livros e internet.

Com base nos elementos que constituíam a cidade, como carroças, cavalos, ruas de paralelepípedo, avanço da erva-mate que permeia a nossa história, contribuindo para a emancipação política do Paraná e a alteração das nossas paisagens, as fontes e os chafarizes, que contam um pouco da história da cidade, como a conhecida "Cavalo Babão" (originalmente chamada "Fonte da Memória"), localizada no centro da cidade (Largo da Ordem), relembrando a história dos colonos que levavam seus cavalos para beber água na região, os sinos das igrejas, enfim, foi preciso que os estudantes compreendessem melhor o contexto histórico e sua paisagem geográfica para só assim criar uma paisagem sonora.

Dessa forma, estabelecemos um cronograma para a elaboração do material, a fim de que os estudantes entendessem a importância de planejamento e organização para que o resultado esperado fosse alcançado e para que os demais conteúdos necessários às aulas de Arte continuassem a ser estudados. 
Cidade viva e sonora da terra de Guairacá: experimentações sonoras acerca da história de Curitiba...

Quadro I - Cronograma de atividades

\begin{tabular}{|l|l|}
\hline \multicolumn{1}{|c|}{ Datas } & \multicolumn{1}{c|}{ Atividades } \\
\hline $22 / 04 / 2019$ & Divulgação do edital \\
\hline $07 / 06 / 2019-15 / 06 / 2019$ & Inscrições \\
\hline $28 / 06 / 2019$ & Resultado do processo seletivo \\
\hline $26 / 07 / 2019$ & $\begin{array}{l}\text { Conversa com os estudantes, organização e distribuição } \\
\text { de tarefas }\end{array}$ \\
\hline $31 / 07 / 2019$ & $\begin{array}{l}\text { Estudo e pesquisa sobre a história de Curitiba e do } \\
\text { Paraná }\end{array}$ \\
\hline $02 / 08 / 2019$ & $\begin{array}{l}\text { Estudo e pesquisa sobre a história de Curitiba e do } \\
\text { Paraná }\end{array}$ \\
\hline $09 / 08 / 2019$ & Gravações \\
\hline $16 / 08 / 2019$ & Gravações \\
\hline $21 / 08 / 2019$ & Gravações \\
\hline $23 / 08 / 2019$ & Gravações \\
\hline $28 / 08 / 2019$ & Edição \\
\hline $30 / 08 / 2019$ & Envio da composição musical \\
\hline $09 / 09 / 2019-22 / 09 / 2019$ & $\begin{array}{l}\text { Mostra da IV Bienal de Arte/Educação no Portão Cultural } \\
\text { e Unidades de Ensino }\end{array}$ \\
\hline $11 / 09 / 2019$ & $\begin{array}{l}\text { Visita dos estudantes e professores da escola } \\
\text { participantes da Bienal no Portão Cultural }\end{array}$ \\
\hline
\end{tabular}

Fonte: Elaborado pelos autores, 2019.

Para representar os elementos escolhidos, fizemos uma pesquisa sonora, pela qual os alunos foram motivados a descobrir diferentes sonoridades, seja por meio de instrumentos musicais, empreendendo "novos meios de produção sonora" (ZAGONEL, 1999, p. 10) ou de qualquer objeto ou material que pudesse reproduzir algum som, ou ainda, utilizando sons vocais e corporais diversificados, buscando assim a criação da paisagem sonora desejada, fazendo com que o ouvinte pudesse imaginar o cenário proposto.

Zagonel (1999) ao citar os estudos de Anne Bustarret (1982) conclui que "as crianças escutam melhor quando "fazem", e melhor ainda quando gravam o que fazem" (Ibid., p. 5). A autora ainda destaca que "o fato de bem escutar o mundo sonoro, e de brincar com os sons, leva à música contemporânea" (Ibid.).

Assim, ao final de toda essa pesquisa sonora, foram selecionados os sons que segundo os alunos mais se ajustavam a cada elemento representativo, para assim darmos sequência ao processo de criação musical. 
Quadro 2 - Elementos simbolizando cada década e seu respectivo som

\begin{tabular}{|l|l|}
\hline \multicolumn{1}{|c|}{ Elementos representativos } & \multicolumn{1}{c|}{ Instrumentos/objetos/materiais } \\
\hline Carroça & Arranha-fone (objeto sonoro feito com garrafa PET) \\
\hline Cavalo & Coco (instrumento de percussão) \\
\hline Fontes de água & Pau-de-chuva (instrumento de percussão) \\
\hline Erva-mate & Folhas secas; sacolas \\
\hline Construção de ferrovias & Clavas; castanholas; ganzá; colheres; baquetas \\
\hline Chuva & Tampinhas de garrafa pet; caxixi; percussão corporal \\
\hline Cancela do trem & $\begin{array}{l}\text { Flauta doce (assoprar nos orifícios alternadamente, e na } \\
\text { parte da cabeça - o apito) }\end{array}$ \\
\hline Ônibus & Vozes de pessoas conversando \\
\hline Caminhão & Caixas e carrinho de supermercado arrastando; vozes \\
\hline Sinos & Triângulo (instrumento de percussão) \\
\hline Bicicleta & Bicicleta de um professor \\
\hline Vendedores/feirantes & Vozes \\
\hline Pessoas andando & Percussão corporal \\
\hline Vento & Sons com a boca \\
\hline Pássaros & Assovios \\
\hline Crianças brincando & Jogos de mãos; simulação de uma partida de futebol \\
\hline
\end{tabular}

Fonte: Elaborado pelos autores, 2019.

A maior dificuldade foi o momento das gravações, pois precisávamos de um ambiente silencioso e não tínhamos equipamento próprio para tal, a fim de isolar apenas o som que queríamos gravar, evitando ruídos externos à proposta. Além disso, não tínhamos uma sala específica para a disciplina de Arte. $O$ ambiente mais silencioso que encontramos foi a sala de educação física, que fica mais afastada das outras salas, da quadra e do pátio da escola, e utilizamos o próprio notebook para as gravações.

Após a gravação do material sonoro, começamos a pensar em como deixar mais claro para o ouvinte essa evolução no processo de urbanização/industrialização da cidade de Curitiba ao longo do século XX. Portanto, para simbolizar a transição de uma década a outra, utilizamos um trecho musical de composições que fizeram sucesso no Brasil em cada época, incluindo músicas brasileiras e internacionais. Para isso, realizamos uma pesquisa sobre quais seriam elas, sendo necessário fazer uma seleção, pois em uma mesma década tivemos várias obras musicais de grande sucesso. 
Quadro 3 - Músicas selecionadas

\begin{tabular}{|l|l|}
\hline \multicolumn{1}{|c|}{ Década (século XX) } & \multicolumn{1}{c|}{ Músicas (Composição elou intérprete) } \\
\hline 1900 & Ô abre alas - Chiquinha Gonzaga \\
\hline 1910 & Apanhei-te cavaquinho - Ernesto Nazareth \\
\hline 1920 & My blue heaven - Walter Donaldson e George A. Whiting \\
\hline 1930 & Over the rainbow - Harold Arlen e Yip Harburg \\
\hline 1940 & Tico-tico no fubá - Zequinha de Abreu \\
\hline 1950 & The great pretender - The Platters \\
\hline 1960 & Love me do - The Beatles \\
\hline 1970 & Got to be real - Cheryl Lynn \\
\hline 1980 & Thriller - Michael Jackson \\
\hline 1990 & The rhythm of the night - Corona e Olga de Souza \\
\hline 2000 & Oração - A banda mais bonita da cidade \\
\hline
\end{tabular}

Fonte: Elaborado pelos autores, 2019.

A composição final teve 8 minutos e 20 segundos de duração, reproduzida em looping, ou seja, a gravação foi tocada repetidamente sem pausas. Foram utilizados aparelhos de reprodução sonora (cúpula sonora), onde um grupo de estudantes se posicionava embaixo, para ter essa experiência estética auditiva, enquanto passavam imagens (em duas paredes brancas) do processo de criação musical, proporcionando também uma experiência estética visual.

Para a visita ao Portão Cultural, os alunos levaram um bilhete de autorização a ser assinado pelo responsável, permitindo a saída da escola para o local da mostra. Todos os estudantes receberam essa permissão.

Durante a visita à mostra da IV Bienal, realizada no dia II de setembro de 20I9, por meio da mediação de profissionais da equipe da SME e da Fundação Cultural de Curitiba, os alunos e professores puderam conhecer e apreciar algumas das propostas artísticas, selecionadas para o Portão Cultural. Entre elas, temos:

Quadro 4 - Propostas artísticas apreciadas

\begin{tabular}{|l|l|}
\hline \multicolumn{1}{|c|}{ Título da Proposta artística } & \multicolumn{1}{|c|}{$\begin{array}{c}\text { Escola (EM) ou Centro de Educação Infantil } \\
\text { (CMEI) }\end{array}$} \\
\hline A arte de brincar & EM CEl Issa Nacli \\
\hline A arte em nós: o olhar das crianças da Educação Infantil & CMEl Nelson Buffara \\
\hline A arte que me (re)veste & EM Arapongas \\
\hline A exploração sonora: no contexto da Educação Infantil & CMEl Uberlândia \\
\hline $\begin{array}{l}\text { Cápsula de teletransporte: do imaginário ao real, } \\
\text { vamos experimentar? }\end{array}$ & CMEl Vila Torres \\
\hline Brincando com Miró & CMEl Gerdt Guenther Hastchbach \\
\hline Cidade viva e sonora da terra de Guairacá & EM Araucária \\
\hline
\end{tabular}


João Paulo de Souza da Silva; Daniele Martinez de Oliveira Coelho

\begin{tabular}{|l|l|}
\hline Com quantos pontos se borda uma história? & CMEl Solitude \\
\hline Coral de clavas & EM São Miguel \\
\hline Cro'lorindo & CMEl Irmã Dorothty Mae Stang \\
\hline Desenhar vivenciar o imaginário & CMEl Parque Industrial \\
\hline Encantos do bosque & CMEl Jardim Aliança \\
\hline $\begin{array}{l}\text { Entre o gesto e o sensível: um olhar sobre a nossa } \\
\text { cidade }\end{array}$ & EM Colombo \\
\hline Modelando expressões & EM Arapongas \\
\hline Mulheres que mudaram o mundo & $\begin{array}{l}\text { EM Bairro Novo do CAIC Guilherme Lacerda Braga } \\
\text { Sobrinho }\end{array}$ \\
\hline O menino que descobriu o vento & CMEl Sonho de Criança \\
\hline Obra viva & CMEl Vila Ipiranga \\
\hline
\end{tabular}

Fonte: Secretaria Municipal de Educação de Curitiba, 2020.

Em 2020, a Secretaria Municipal da Educação de Curitiba lançou um livro sobre a Bienal de Arte/Educação da SME, contendo informações como: O Seminário (p. 24), Encontro entre Curadores (p. 4I), O Edital (p. 43), IV Bienal de Arte/Educação da SME (p. 47), Sobre o Portão Cultural (p. 52), Categoria Portão Cultural (p. 55), Categoria Unidade Educacional (p. 159). Segundo a SME, a IV Bienal de Arte/Educação, realizada de 9 a 22 de setembro de 2019, foi

[...] resultado do trabalho em Arte/Educação, desenvolvido com as crianças e estudantes de todas as idades, além de profissionais da educação, em 53 unidades educacionais do Município. Com o tema "Arte e Vida: fronteiras em aberto", a IV Bienal buscou estabelecer um diálogo com a Arte Contemporânea e as produções artísticas realizadas nas unidades educacionais, com vistas à ampliação do olhar estético para os processos educativos e criativos. Essa mostra refletiu sobre os desdobramentos da relação entre arte e vida nas diferentes linguagens artísticas, promovendo o hibridismo entre as linguagens da arte, as tecnologias, assim como o protagonismo dos estudantes e dos profissionais da educação. (CURITIBA, 2020, p. 7).

Nas páginas 82 e 83 do referido livro é possível encontrar algumas informações, bem como fotos do trabalho aqui exposto. Segundo a obra mencionada, em 22 de abril de 2019 foi divulgado o edital e de 7 a 15 de junho foram realizadas as inscrições.

Foram recebidas 132 inscrições e propostas, avaliadas durante o mês de junho pela Comissão Técnica de Análise de Projetos Culturais. Dessas, 53 foram selecionadas para o Portão Cultural e 17 para as unidades educacionais. Muitas propostas não foram aprovadas por não estarem de acordo com o Edital, como propostas em branco, incompletas ou fora do padrão. (CURITIBA, 2020, p. 46).

O edital disponibilizou nove modalidades de apresentação artística: I - Performance; II - No palco; III - Intervenção literária; IV - Exploração e produção sonora; V - Expressões e formatos; VI - 
Arte e mídia: VII - Vídeos; VIII - Intervenção pública interativa temporária; IX - Laboratório (CURITIBA, 2020, p. 44), a fim de proporcionar diferentes práticas contemporâneas. A proposta artística aqui relatada participou na modalidade IV - Exploração e produção sonora.

Cabe ressaltar que ainda no ano de 2008 foi sancionada a lei n. 11.769 , em 18 de agosto, que estabeleceu a obrigatoriedade do ensino da música na educação básica, reforçando a necessidade do ensino dos conteúdos dessa área da disciplina de Arte, que já constava nas diretrizes curriculares.

Assim, ao longo desse relato de experiência sobre a proposta artística "Cidade viva e sonora da terra de Guairacá", apresentamos como foi o processo de exploração e experimentação sonora, as pesquisas realizadas, o percurso para a captação e gravação da paisagem sonora acerca da história de Curitiba no século $X X$ com estudantes do $5^{\circ}$ ano E da EM Araucária, apresentada na IV Bienal de Arte/Educação da SME de Curitiba, bem como referenciais sobre as artes integradas, paisagem sonora e música contemporânea.

Como vimos, a BNCC traz uma novidade para o ensino de Arte na escola, as Artes Integradas, buscando proporcionar aos estudantes uma experiência mais conectada entre as diferentes linguagens artísticas (música, dança, teatro e artes visuais). Além disso, essa proposta propicia uma abordagem articulada com $\circ$ uso das tecnologias da comunicação e informação, bem como sugestões que relacionam as várias áreas do conhecimento (Educação Física, História, Matemática etc.), dialogando com as diferentes linguagens artísticas, possibilitando o desenvolvimento global do aluno.

\section{Considerações Finais}

Embora a integração das artes possa ser extremamente positiva para a formação dos estudantes, é essencial lembrar que é uma abordagem complexa, uma vez que exige do docente o trabalho com elementos em comum das diferentes linguagens artísticas de forma progressiva, tendo relação com os temas trabalhados e a realidade dos estudantes e da comunidade onde a escola está inserida. É evidente que de forma alguma as linguagens artísticas operam de maneira isolada, sempre existindo interfaces que estabelecem diálogos mínimos entre elas, porém, na abordagem das artes integradas elas caminham juntas, formando uma rede interligada entre os diferentes saberes. É fundamental um conhecimento aprofundado e crítico do currículo, pois sua desconexão impossibilita as diferentes relações que devem ser desenvolvidas nesse processo.

No que tange à arte contemporânea, é importante lembrar que os alunos saberão apreciar melhor a música contemporânea, por exemplo, a partir do momento em que começarem a explorar, experimentar e criar.

O trabalho com a paisagem sonora (soundscape composition), em seu resultado, culmina em uma 
composição de música contemporânea, sendo que essa proposta possibilita uma escuta mais ativa, reflexiva e consciente dos ambientes que nos cercam. Além disso, quando observamos um cenário que não faz parte da nossa vivência, como a paisagem sonora da cidade de Curitiba no passado (século $X X)$, nos faz pensar na evolução da nossa paisagem sonora atual.

A paisagem sonora remete-nos ao nosso ambiente, proporcionando sons agradáveis ou não. Isso vai depender de cada ouvinte. Para algumas pessoas, por exemplo, ouvir uma buzina pode ser muito desagradável, o que para outras, pode passar despercebido.

Quando refletimos sobre a história da nossa cidade, percebemos que alguns elementos que antes eram extremamente importantes e usados, hoje foram substituídos por outros. $O$ som produzido em uma paisagem em determinados espaços/tempos concede ao lugar uma identidade sonora única. Na Curitiba de antigamente, por exemplo, o movimento constante de carroças e cavalos deu lugar ao barulho dos motores, buzinas e aparelhos de som veicular da atualidade. Com isso, foi possível discutir a relação do seu processo de urbanização/industrialização com o aumento do número de sons e ruídos no espaço curitibano.

Durante o percurso para a elaboração do trabalho aqui relatado, alguns desafios e obstáculos precisaram ser transpostos, como a falta de equipamento e ambiente propício para a gravação e o fato de alguns alunos terem tido dificuldade para obter informações a respeito da época escolhida com seus familiares, parentes ou vizinhos mais velhos.

Também foi possível mostrar aos alunos a importância do planejamento e organização para a realização de um trabalho com diversas etapas. Além disso, ao longo desse discurso, conhecemos um pouco do edital, quais as propostas artísticas apreciadas pelos estudantes e professores durante a visita à mostra no Portão Cultural, o resultado da IV Bienal que culminou no livro "Arte e Vida: Fronteiras em Aberto" da Bienal de Arte/Educação da SME, assim como um breve histórico sobre as três primeiras Bienais da SME, chegando até a quarta edição em 2019, cuja proposta artística aqui relatada foi exposta.

Portanto, reconhecemos que os avanços recentes e as propostas atuais, como a Bienal de Arte/Educação, podem levar a uma transformação no ensino de Arte na escola. Entretanto, ainda são necessárias reflexões e ações que permitam a compreensão da Arte como campo do conhecimento, de modo que não seja reduzida a um meio de comunicação para destacar dons inatos ou a prática de entretenimento e terapia. É fundamental que o Brasil possa investir mais recursos na formação (inicial e continuada) de professores, nas pesquisas sobre o ensino e suas metodologias. Assim, o ensino de Arte deixará de ser coadjuvante no sistema educacional para se ocupar também do desenvolvimento do sujeito, frente a uma sociedade construída historicamente e em constante transformação. 


\section{Referências}

BRASIL. Ministério da Educação. Base Nacional Comum Curricular (BNCC): educação é a base. Brasília, MEC/CONSED/UNDIME, 2017. Disponível em:

http://basenacionalcomum.mec.gov.br/images/BNCC_EI_EF_II05I8_versaofinal_site.pdf Acesso em: 29 jun. 2019.

CURITIBA, Secretaria Municipal da Educação. Arte e Vida: fronteiras em aberto. Bienal de Arte/Educação da SME. Curitiba: Heyzine Flipbooks, 2020. Disponível em: https://heyzine.com/flipbook/bd36e2f73a.html Acesso em: 09 fev. 202I.

CURITIBA, Secretaria Municipal da Educação. Caderno Pedagógico de Unidades Curriculares de Transição 2020 - 202I: arte - anos iniciais. Curitiba: SME, 202I. Disponível em: https://mideducacao.curitiba.pr.gov.br/202I/2/pdf/002846I I.pdf Acesso em: 12 fev. 202 I.

OLIVEIRA, L. F. A Emergência do Significado em Música. 264 f. Tese (Doutorado em Música), Universidade Estadual de Campinas, Campinas, 2010. Disponível em: http://repositorio.unicamp.br/bitstream/REPOSIP/283929///Oliveira_LuisFelipe_D.pdf Acesso em: I I fev. 2021 .

SANTOS, F. C. dos. A Paisagem Sonora, a Criança e a Cidade: exercícios de escuta e de composição para uma ampliação da ideia de música. 2006. Tese (Doutorado em Música).

Universidade Estadual de Campinas, Campinas, 2006. Disponível em:

http://repositorio.unicamp.br/bitstream/REPOSIP/28433I/I/Santos_FatimaCarneirodos_D.pdf Acesso em: II fev. 202I.

SCHAFER, R. M. A Afinação do Mundo: uma exploração pioneira pela história passada e pelo atual estado do mais negligenciado aspecto do nosso ambiente: a paisagem sonora. Tradução de Maria Trench de O. Fonterrada. São Paulo: Editora Unesp, 200I. Disponível em:

https://monoskop.org/images/9/93/Schafer_R_Murray_A_afinacao_do_mundo.pdf Acesso em: 12 fev. 2021.

SCHAfER, R. M. O Ouvido Pensante. Tradução de Maria Trench de O. Fonterrada; Magda R. Gomes da Silva; Maria Lúcia Pascoal. São Paulo: Fundação Editora da UNESP, I99I. Disponível em: https://monoskop.org/images/2/2I/Schafer_R_Murray_O_ouvido_pensante.pdf Acesso em: 12 fev. 2021 .

SOUZA LIMA BLOG. O Que é Música de Câmara? Souza Lima Blog. Curitiba, 26. fev. 2019. Disponível em: https://souzalima.com.br/blog/o-que-e-musica-de-camara/ Acesso em: 12 fev. 2021.

TOFFOLO, R. B. G.; OLIVEIRA, L. F; ZAMPRONHA, E. S. Paisagem Sonora: uma proposta de análise. In: $14^{\circ}$ Encontro da ANPPOM, 2003, Porto Alegre. Anais [...] Porto Alegre: ANPPOM, 2003. Disponivel em: http://cogprints.org/3000/I/TOFFOLO_OLIVEIRA_ZAMPRA2003.pdf Acesso em: I I fev. 2021.

TORRES, M. A.; KOZEL, S. Paisagens Sonoras: possíveis caminhos aos estudos culturais em geografia - Soundscapes: possible ways to study in cultural geography. R. RA'E GA, Curitiba, n. 20, p. I23132, 20 I0. Disponível em: https://revistas.ufpr.br/raega/article/view/206/6/I3762 Acesso em: 29 jun. 2019. 
ZAGONEL, B. Descobrindo a Música Contemporânea. In: Arte Contemporânea em Questão. Joinville, SC: UNIVILLE/Instituto Schwanke, 2007. Disponível em:

https://www.bernadetezagonel.com.br/ASSETS/pdf/Descobrindo-a-Musica-Contemporanea.pdf Acesso em: 29 jun. 2019.

ZAGONEL, B. Em Direção a um Ensino Contemporâneo de Música. Revista Ictus, Salvador: UFBA, v.I, p. I-I5, 1999. Disponível em: https://periodicos.ufba.br/index.php/ictus/article/view/34196 Acesso em: 09 fev. 2021 .

Recebido em: 27 de fevereiro de 202I.

Versão corrigida recebida em: 27 de agosto de 202I.

Aceito em: 27 de agosto de 2021 .

Publicado online em: 25 de fevereiro de 2022. 